\title{
Crossing boundaries, hitting barriers
}

\author{
Interdisciplinary research may be lauded, but it's not yet rewarded.
}

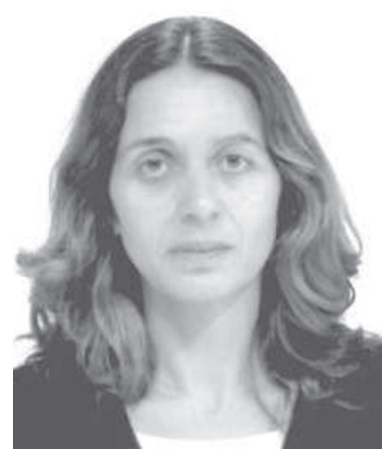

Adina Payton

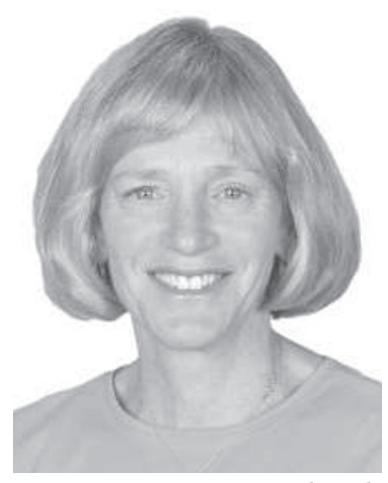

Mary Lou Zoback
The scientific community recognizes the importance of interdisciplinary research. But institutions have not yet caught up with ways to reward good examples of it. In fact, interdisciplinary research in academia often faces discouraging barriers. Working across disciplines requires not only depth of knowledge but also a holistic understanding of complex systems. But the tenure system largely favours narrowly focused research in subdisciplines.

Much progress in our field, Earth sciences, has emerged from working across several disciplines. Combining medicine and geophysics is resulting in new medical devices. Mixing meteorology and biology provides new ways of looking at the spread of infectious disease. And blending oceanography and atmospheric science leads to a better understanding of the causes and consequences of global warming. We need to continue and expand these multidimensional approaches to benefit humanity and improve the prediction of climate and natural hazards, and to provide sciencebased solutions that support human well-being and the sustainable use of our resources.

The 2006 US National Academies report Rising Above the Gathering Storm: Energizing and Employing America for a Brighter Economic Future emphasizes the value of interdisciplinary research, noting that many significant scientific and engineering advances cut across several disciplines.

Academia has taken some steps to embrace interdisciplinary research. The Harvard University Center for the Environment programme recognizes that the most pressing problems facing the environment are complex and often require collaborative investigation by scholars versed in different disciplines. Similarly, the new Woods Institute for the Environment at Stanford University is an interdisciplinary hub for research, teaching and problem-solving that draws on the experience and expertise of faculty members and students from all seven schools at Stanford University.

But the university reward system has generally not kept pace with this approach. Most universities still rely on a tenure process that judges excellence and leadership in a narrowly defined disciplinary (or subdisciplinary) field.

Indeed, a 2004 National Academies report, Facilitating Interdisciplinary Research, lists "promotion criteria" as the top impediment to interdisciplinary research, based on separate rankings by both scientists and university provosts. "An interdisciplinary faculty member seeking tenure often faces two challenges beyond those faced by members working in a single discipline," says the report. "First, interdisciplinary research done

\section{"If universities want to attract innovative young researchers, they should support integrative research."}

by the candidate may not be valued sufficiently to compensate for lower output of disciplinary research ... Second, it can be difficult to find reviewers who understand the overall quality of the work, which usually lies outside the expertise of people on the tenure evaluation committee."

The committee recommended that institutions provide more flexibility in promotion and tenure procedures, recognizing that the contributions of someone in interdisciplinary research may need to be evaluated differently from those of someone in a single-discipline project. Indeed, if universities want to attract and retain innovative young researchers and foster novel approaches to science, they should support infrastructure, research needs and opportunities for integrative research. They also need to find different ways of rewarding and evaluating scientists who are engaged in such research.

We advocate several steps towards proper recognition of the contributions of interdisciplinary researchers. They include establishing interdisciplinary review committees to evaluate faculty members who are conducting such research, with at least one of the committee members actively doing interdisciplinary work themselves. We'd like to see tenure committees solicit input from scientists personally familiar with the candidate's work - people who can assess individual contributions to collaborative projects and roles in facilitating the research. Letters to external referees should be formulated to emphasize the transdisciplinary nature of the candidate's work and not require that the candidate be identified as or compared with an expert in one specific field. Interdisciplinary researchers could also have more time to reach tenure milestones, as their research can be more time-consuming to coordinate, conduct and synthesize.

Interdisciplinary research and education are inspired by the drive to provide effective solutions to complex questions. A central problem it faces is in finding ways to remove those barriers.

Adina Paytan is in the Department of Geological and Environmental Sciences at Stanford University. Mary Lou Zoback is vice-president of earthquake risk applications at Risk Management Solutions in Newark, California.

Facilitating Interdisciplinary Research www.nap.edu/openbook/ 0309094356/html/R1.html 